\title{
Is the future now?
}

\author{
Neuro: The New Brain Sciences and \\ the Management of the Mind \\ Nikolas Rose and Joelle M. Abi-Rached \\ Princeton University Press; 2013
}

$\mathrm{O}$ ver the past three decades, British sociologist Nikolas Rose has been describing a widespread tendency in the affluent West to explain an entire range of personal and societal problems in terms of molecules. His 2007 book, The Politics of Life Itself: Biomedicine, Power, and Subjectivity in the Twenty-First Century, shows how biotechnology has expanded into medical practice, shifting the role of health care beyond the management of sickness to the management and optimization of health. ${ }^{1}$ $\mathrm{He}$ argues that screen-and-intervene policies have come together with technologies across a spectrum from plastic surgery to antidepressants, aimed at making people the best they can be. Emerging in this high-tech culture is a new way of living as a health consumer, a kind of life in which the pursuit of health leads to strong connections between citizens and medical authorities, governments, employers, insurers and the biotech industry. ${ }^{1}$ Neuro: The New Brain Sciences and the Management of the Mind, a collaboration between Rose and historian Joelle M. Abi-Rached, is a continuation of this analysis.

Drawing on novel imaging techniques, behavioural genetics, animal models and neuroplasticity research, the central argument of Neuro is that a molecular gaze is making it possible for medicine to view people in terms of biology rather than in terms of a deep interior psychological space. Mental medicine in the West sees everything from Alzheimer disease to anxiety, from addictions to obesity, as a brain disorder. Health consumers, embracing this new

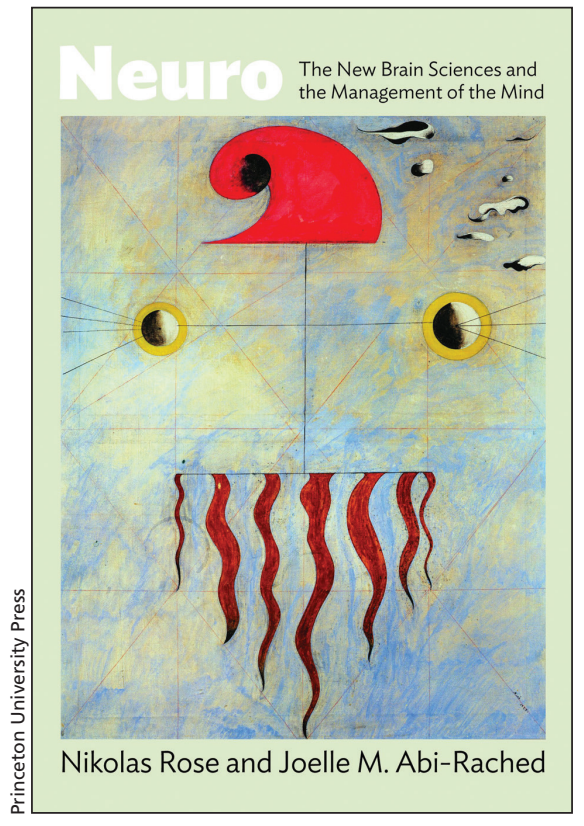

point of view, feel obliged to take responsibility for their biology, to place their faith in the hypothesis of neuroplasticity and manage their brains as part of the responsibilities of freedom.

How far will the enthusiasm for neuroscience go? Taken to an extreme, we end up in a world in which "physics would explain chemical laws; chemistry would predict what happens to living bodies; [and] biology would be able to explain psychological makeup and social relations." 2 Of course, readers of this journal are well aware of a gap between the promises and the products of research. ${ }^{3}$ Yet they may not know that philosophers, sociologists, economists and even legal scholars are now looking to the neurosciences for answers. But why should doctors care about speculative research in a field whose reach seems to have exceeded its grasp?

To dismiss the neurosciences as oversold would be to miss the point of their cultural currency. Compelling brain models and images already in circulation are often interpreted literally, proof, as one analyst has put it, "that there really is a reality beyond representations, which can now be located in the brain." If history is any indication, many aspects of this new reality will have been drawn from and will reinforce existing social structures. As philosopher of biology George Canguilhem has observed, the boundary between normality and pathology is not set in a laboratory but in society itself. And because we as doctors are arbiters of the normal and the pathological, bridges between the laboratory and the suffering individual, it is important to be aware that we live in a culture that increasingly looks to molecules for answers.

Far from taking readers on a journey of progress in which neuroscience is either an inevitable solution to society's problems or a symptom of an emerging dystopia that will eventually use biotechnology to restrict human freedom, Rose and Abi-Rached paint a balanced picture. To many, a new form of personhood is emerging, based on neurons that have finally achieved the ability to observe themselves. Neuro is a highly readable, optimistic work that simultaneously examines the shortfalls of this view while holding out hope that "neuroscience should become a genuinely human science."

\section{Dorian Deshauer MD MSc}

Associate editor, CMAJ

Toronto, Ont.

\section{References}

1. Rose N. The politics of life itself: biomedicine, power, and subjectivity in the twenty-first century. Princeton (NJ): Princeton University Press; 2007.

2. Mol A. Body multiple: ontology in medical practice. Durham (NC): Duke University Press; 2002.

3. Alda M. Personalized psychiatry: many questions, fewer answers. J Psychiatry Neurosci 2013;38: 363-5.

4. Cooter R, Stein C. Writing history in the age of biomedicine. New Haven (CT): Yale University Press; 2013

CMAJ 2014. DOI:10.1503/cmaj.131814 